\title{
Setting Reaction of Zinc Oxide and Eugenol ${ }^{1}$
}

\author{
Henry I. Copeland, Jr., ${ }^{2}$ Gerhard M. Brauer, W. T. Sweeney, and A. F. Forziati
}

Zinc oxide-eugenol mixtures have been used in dentistry for a number of years. The setting mechanism of these mixtures was investigated. X-ray diffraction data and electron photomicrographs give evidence that a crystalline compound is formed. Analysis and molecular-weight determinations show that this compound corresponds to the empirical formula $\left(\mathrm{C}_{10} \mathrm{H}_{11} \mathrm{O}_{2}\right)_{2} \mathrm{Zn}$, zinc eugenolate. Infrared data, as well as the nonreactivity of meta and para substituted phenols as compared to the ortho isomers, suggest that the zinc eugenolate is a chelate. The hardened mass consists of zinc oxide embedded in a matrix of long sheath-like crystals of zinc eugenolate. The excess eugenol is sorbed by both the zinc eugenolate and the zinc oxide.

\section{Introduction}

Zinc oxide-eugenol materials have been developed for utilization in a number of dental applications. They are most widely employed as palliative and antibacterial agents in the treatment of carious lesions [1]. ${ }^{3}$ With modifiers, these materials are used as impression pastes and as surgical cements.

Generally, the use of zinc oxide and eugenol depends on their tendency to form a hardened coherent mass when mixed. Unexplained variations in the behavior of the mixtures are important to the clinician who uses these materials to treat dental conditions. Of special concern are variations in setting rate, hardness, and strength of the set mass.

The mechanism of the setting process of zinc oxide and eugenol is unknown. Factors that have been reported to produce variations in the physical behavior are the type of zinc oxide used, the amount of water present (both in the zinc oxide and atmosphere), and the ambient temperature. The following theories have been advanced in regard to the setting process: 1 . The setting process is a purely physical one in which the constituents retain their individuality [2]; 2, a chemical reaction occurs and a compound resembling zinc phenolate is formed [3]; and 3 , the setting process is a combination of physical and chemical reactions [3].

The object of this investigation was to study the setting of zinc oxide and eugenol mixtures in order to more nearly define physical and chemical processes involved.

\section{Experimental Procedures}

\subsection{Materials}

The zinc oxide (reagent grade) used had a particle size of around $3000 \mathrm{~A}$ in diameter and contained less than 2 percent of water. It was white. An experi-

\footnotetext{
1 The data in this publication were presented in a thesis by Henry I. Copeland, $\mathrm{Jr}$., in partial fulfillment of the requirements of the Graduate School of Georgetown University, Washington, D. C., for the degree of Master of Science.

This paper was presented to the International Association for Dental Research, Chicago, March 1955; and to the Medicinal Division, American Chemical Society, Cincinnati, April 1955.

${ }_{2}$ Guest worker at the National Bureau of Standards, and member of the Dental Corps, U, S, Air Force.

3 Figures in brackets indicate the literature references at the end of this paper.
}

mental type of zinc oxide (Merck Hyperfine) was also used. According to the manufacturer's specifications it had a particle size of 125 to $250 \mathrm{~A}$ in diameter and contained approximately 5 percent of water. This zinc oxide was reddish in color.

The eugenol was USP grade. All other chemicals used were reagent grade.

\subsection{Setting of Mixtures}

Mixes of zinc oxide (reagent grade) were made with guaiacol, methylguaiacol, eugenol, phenol, veratrole, safrol, anethole, $m$-methoxyphenol, and thymol. The mixtures were made with a stellite spatula on a glass slab at room temperature. It was necessary to melt the phenol and thymol prior to mixing. The maximum amount of zinc oxide that could be wetted by the liquids was incorporated.

Setting time was determined by means of a penetrometer. A modification of the ASTM Penetration Test for Bituminous Materials was used with a $100-\mathrm{g}$ load for 5 sec and 116 -in. needle. The tests were made at room temperature, and the material was considered set when the needle could no longer penetrate the material or three successive penetrations at 30-sec intervals gave identical values.

Samples of the zinc oxides were dehydrated by heating at $110^{\circ} \mathrm{C}$ for $24 \mathrm{hr}$. The dehydrated zinc oxides were mixed with eugenol in the same manner.

\subsection{Temperature Change During Setting}

The change in temperature caused by the reaction was determined by means of a calibrated ironconstantan thermocouple connected to a recording potentiometer. Zinc oxide (Hyperfine)-eugenol mixtures were used in this experiment.

\subsection{Analysis for Reaction Products}

Mixtures of 0.5 -mole zinc oxide (reagent grade) and 0.1-mole eugenol were prepared. The hardened mass was pulverized by grinding in a mortar to a fine powder. The particles were extracted with chloroform for $30 \mathrm{hr}$ in a Soxblet extractor. The residue left in the filter thimble was vacuum-dried and weighed. The chloroform was distilled off from the 
extract and the residue distilled over at $87^{\circ}$ to $101^{\circ} \mathrm{C}$ and $2-\mathrm{mm} \mathrm{Hg}$ pressure.

Equimolar mixtures of zinc oxide (Hyperfine) and eugenol were prepared and extracted as above. The residue in the filter thimble was dried to constant weight at $110^{\circ} \mathrm{C}$ and 1 - to $2-\mathrm{mm} \mathrm{Hg}$ pressure. The extract was filtered through a weighed Gooch crucible and the residue purified by washing with three $10-\mathrm{ml}$ portions each of chloroform, methanol, and ether and dried to constant weight. This residue was a white crystalline material, which was examined by X-ray diffraction. The elementary analysis, molecular weight, dissociation temperature, crvstal form, refractive index, fluorescence, and density of this residue were determined.

The low-boiling solvents used for extraction and washing were distilled off from the filtrate, and the weight, refractive index, and boiling point of the remaining liquid were determined.

The experiments were repeated, using methanol, benzene, and chlorinated hydrocarbons other than chloroform as the extraction solvent.

\subsection{Measurement of X-ray Diffraction}

The X-ray diffraction measurements were made by the Section on Constitution and Microstructure at the Bureau. The instrument used was a diffractometer utilizing a Geiger counter and a recording potentiometer. All measurements were made through 90 deg. Patterns were obtained of zinc oxide (reagent grade), zinc oxide (Hyperfine), eugenol, mixtures of eugenol with each of the two zinc oxides, and a mixture of zinc oxide (Hyperfine) with guaiacol. Patterns were also obtained of the purified reaction product and a zinc oxide-water mixture.

\subsection{Elementary Analysis ${ }^{4}$}

The purified reaction product was analyzed for carbon, hydrogen, and zinc content, using microtechniques. The dry combustion method was used for the carbon and hydrogen determinations, whereas the zinc was determined as the sulfate by digestion in the presence of sulfuric acid.

\subsection{Infrared Studies ${ }^{5}$}

Zinc 8-quinolinolate was prepared according to Zetzsche [4]. Zine guaiacolate was obtained on mixing guaiacol with zinc oxide. The unreacted guaiacol was removed by repeated washing with cold chloroform. The infrared absorption spectra of 8-quinolinol, zinc 8-quinolinolate, eugenol, zinc eugenolate, guaiacol, and zinc guaiacolate were measured. The solid samples were incorporated in potassium bromide pellets. All samples were examined with a Perkins-Elmer, model 21 spectrophotometer.

4 Elementary analyses were performed by R. A. Paulson.

Infrared absorption spectra were made by J. E. Stewart and G. Wyman.

\subsection{Electron Micrographs ${ }^{6}$}

Electron micrographs of the Hyperfine zinc oxide-eugenol mixture and the purified reaction product were made at 10,000- and 4,000-diameter magnifications, respectively.

\subsection{Water Sorption Study}

Dried zinc eugenolate samples were placed in a desiccator over a saturated potassium nitrate solution (93.3-percent relative humidity at $30^{\circ} \mathrm{C}$ ). The samples were removed from the desiccators at various time intervals and weighed. This procedure was repeated until constant weight was obtained.

\section{Results and Discussion}

The mixtures of zine oxide (reagent grade) with eugenol (I), guaiacol (II), or methyl guaiacol (III) set into a hardened mass.<smiles>C=CCc1ccc(O)c(OC)c1</smiles>

I<smiles>COc1ccccc1O</smiles>

III<smiles>COc1cc(C)ccc1O</smiles>

III
These aromatic oils have a methoxy group ortho to a phenolic hydroxy group. Guaiacol has no substituent group in the para position. Methylguaiacol has a methyl group as a para substituent. Eugenol has a para-beta allyl group.

Mixtures of zinc oxide with phenol itself (IV), veratrole (V), safrol (VI), anethole (VII), thymo] (VIII), and $m$-methoxyphenol (IX) did not harden.<smiles>Oc1ccccc1</smiles><smiles>C/C=C/c1ccc(OC)cc1</smiles>

VII<smiles>COc1ccccc1OC</smiles>

I<smiles>Cc1ccc(C)c(O)c1</smiles>

VIII<smiles>C=CCc1ccc2c(c1)OCO2</smiles>

VII<smiles>COc1cccc(O)c1</smiles>

IX
${ }^{6}$ Electron micrographs were made with F. A. Heckman 
These compounds do not have a methoxy group ortho to a hydroxy group.

From the above considerations, it appears that the para groups are not involved in the setting reaction, and the ortho methoxy group is essential for setting to take place.

The dehydrated zinc oxides did not form a hardened mass when mixed with eugenol. The untreated reagent grade zinc oxide (less than 2 percent of water) required more than $24 \mathrm{hr}$ to set when mixed with eugenol. The Hyperfine zinc oxide-eugenol mixture set in less than $15 \mathrm{~min}$. This zinc oxide had the greater water content (5 percent according to manufacturer) and also had a much larger surface area. In all experiments, the setting rate of either of the zinc oxides mixed with eugenol was more rapid in warm and humid weather than when the relative humidity was low.

The hardening process was found to be exothermic in nature. Rapidly setting mixtures gave a harder product and a greater temperature rise.

On extraction with chloroform the reagent-grade zinc oxide-eugenol mixture yielded approximately 80 percent of eugenol. The residue in the filter thimble showed a 10-percent increase in weight over the original weight of the zinc oxide, and analysis indicated that some eugenol was still in the residue. An insoluble film deposited in the extractor flask suggested some chemical change had taken place.

Because the zinc oxide (Hyperfine)-eugenol mixture had demonstrated faster setting and increased exothermic activity, the extractions were repeated, using this mixture. The following tabulation shows typical results:

\section{BEFORE SETTING}

\begin{tabular}{|c|c|c|}
\hline $\begin{array}{l}\text { Zine oxide (containing } 1.3 \% \text { of } \\
\text { water). }\end{array}$ & $9.60 \mathrm{~g}$ & 0. 117 mole \\
\hline Weight of dry zinc oxide $\ldots \ldots$ & $9.48 \mathrm{~g}$ & \\
\hline Eugenol & $19.26 \mathrm{~g}$ & 0. 117 mole \\
\hline Material in mixture ... & 28. $74 \mathrm{~g}$ & \\
\hline AFTER SF & ING & \\
\hline Residue on extraction & $15.5480 \mathrm{~g}$ & \\
\hline $\begin{array}{l}\text { Residue in extract (other than } \\
\text { eugenol). }\end{array}$ & 1. $1909 \mathrm{~g}$ & \\
\hline Eugenol recovered__._._. & 11. $6676 \mathrm{~g}$ & $65.2 \%$ \\
\hline Material accounted for & 28. $4065 \mathrm{~g}$ & $98.9 \%$ \\
\hline
\end{tabular}

After the chloroform was removed from the extract, the residue soon formed an oily paste. This paste was composed of a white crystalline material and eugenol.

X-ray diffraction measurements were made to determine changes in crystal structure that might have occurred during setting. Both reagent-grade zinc oxide and the Hyperfine zinc oxide gave the characteristic pattern indicating principal spacings of approximately $2.9,2.6$, and $2.5 \mathrm{~A}$. The small particle size of the Hyperfine zinc oxide caused broadening of the bases of the peaks in its pattern. There were no other differences in the diffraction pattern. Eugenol showed no peaks, being noncrystalline.
The mixture of reagent-grade zinc oxide with eugenol showed peaks indicating the presence of a new crystal form with spacings of approximately $17.0,8.8$, and $7.0 \mathrm{~A}$. The zinc oxide (Hyperfine) mixed with eugenol demonstrated the presence of the same crystal form with approximately the same spacings. The peaks were much higher in the pattern of the latter mixture, which indicated the presence of a much greater quantity of the new crystal form. Zinc oxide mixed with guaiacol demonstrated the presence of a new crystal form with spacings of $12.0,9.3$, and $8.7 \mathrm{~A}$. A zinc oxidewater mixture gave only the characteristic zinc oxide pattern.

The diffraction pattern of the purified reaction product showed only the presence of the new crystal form, although as little as 2 percent of zinc oxide could have been detected by the diffractometer used.

Representative X-ray diffraction patterns are shown in figures 1 and 2 . The peaks between 30 and $90 \mathrm{deg}$ have been identified as belonging to zinc oxide [5]. The peaks occurring between 6 and $26 \mathrm{deg}$ are the result of chemical reaction. The reaction product is identified as zinc eugenolate in pattern 1 of figure 2 .
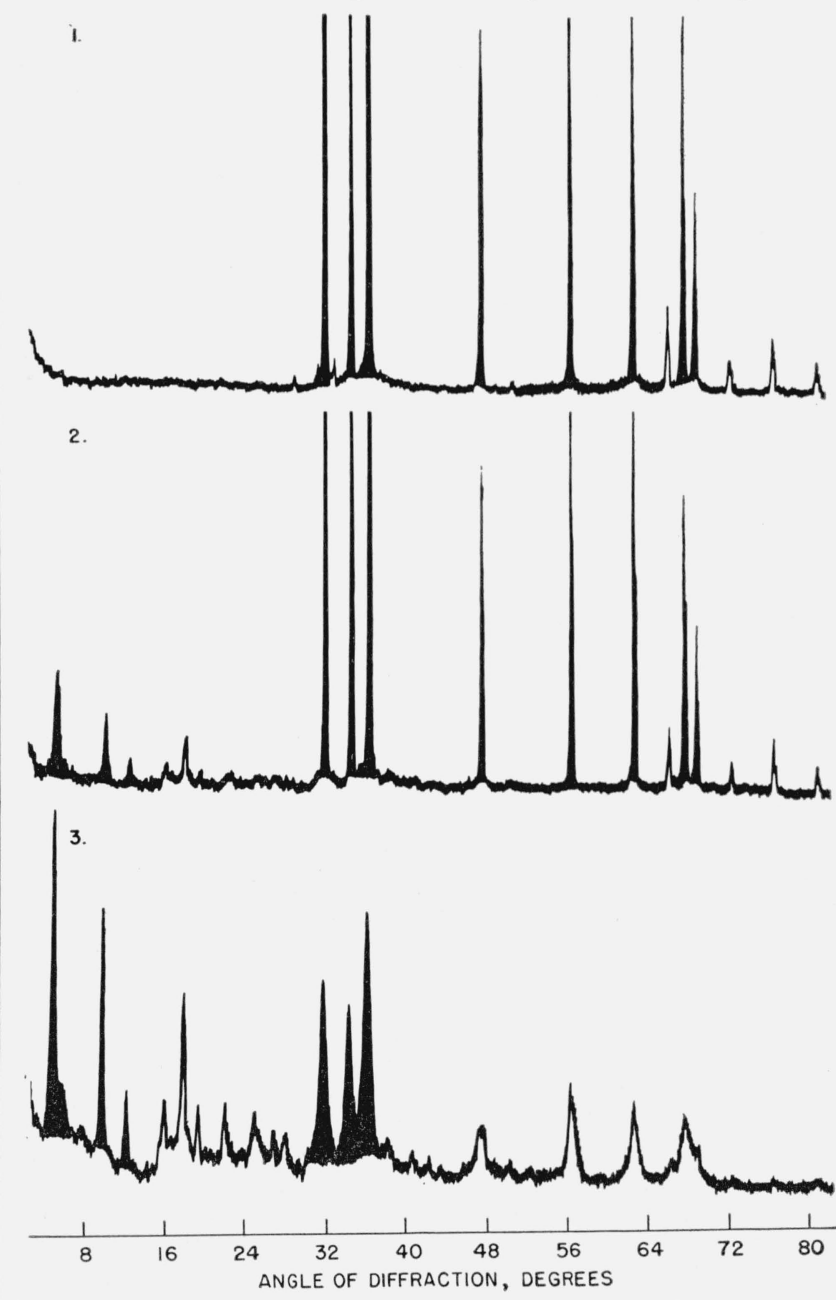

Figure 1. X-ray diffraction patterns.

1, ZnO (reagent); 2, ZnO (reagent)-Eug. mixture; 3, ZnO (Hpf.)-Eug. mixture. 

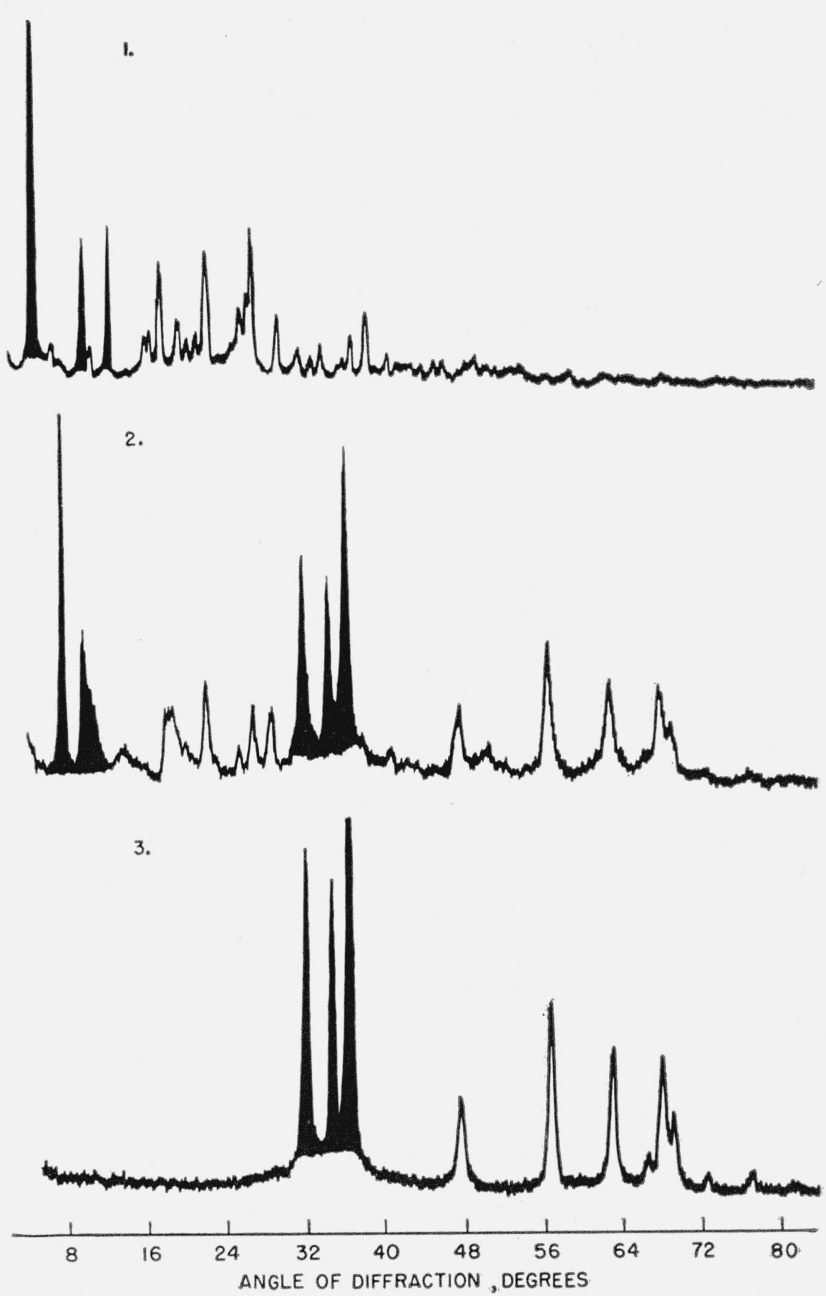

Figure 2. X-ray diffraction patterns.

1, Zinc eugenolate; 2 , $\mathrm{ZnO}$-Guaiacol mixture; $3, \mathrm{ZnO}$-Water mixture.

The analysis of the compound formed by the reaction of zinc oxide and eugenol is given in table 1 . As a compound resembling zinc phenolate had been suggested [3] as a possible reaction product, the composition of zine eugenolate was calculated from the empirical formula and compared with the values obtained for the new crystalline compound. The comparison indicated that the formula for the compound would be that of zinc eugenolate, $\left[\left(\mathrm{C}_{10} \mathrm{H}_{11} \mathrm{O}_{2}\right)_{2} \mathrm{Zn}\right]_{n}$.

The molecular weight was determined cryoscopically in acetamide (molar freezing point depression $K_{f}$ equals $36.3^{\circ} \mathrm{C}$ ). The molecular weight was

TABLE 1. Analysis of reaction product

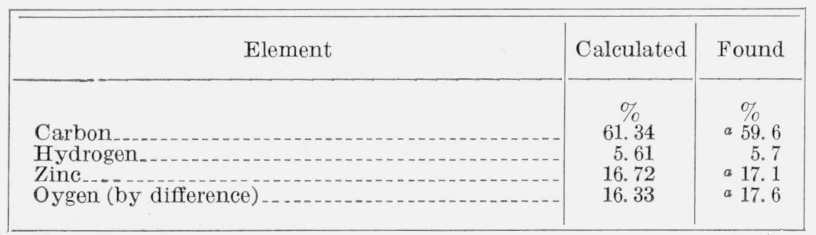

a The low carbon, as well as the high zinc and oxygen percentages, would be explained by the presence of a small amount of zinc oxide in the purified product. found to be 435 . The calculated molecular weight when $n$ equals 1 is 391 . This indicated that the empirical formula for zinc eugenolate is $\left(\mathrm{C}_{10} \mathrm{H}_{11} \mathrm{O}_{2}\right)_{2} \mathrm{Zn}$.

Some physical properties of the zinc eugenolate are given in table 2 .

Zinc eugenolate was found to be insoluble in all common organic solvents, including anisole, mesityl oxide, $\alpha$-chloronaphthalene, dioxanone, $N, N$-diethyl carbamate, ethylene carbonate, diethylphosphite, dimethylamidophosphate, tributylamine, and dimethyl formamide.

Infrared absorption spectra were studied in an attempt to gain more information on the molecular configuration of zinc eugenolate. Zinc 8-quinolinolate was used for comparison because an X-ray analysis of its structure had been reported [6]. For further comparison, guaiacol and the zinc oxideguaiacol reaction product were used.

TABLE 2. Some physical properties of zinc eugenolate

Dissociation temperature _._._._._._. $\mathrm{mp} \ldots 245^{\circ} \mathrm{C}$

Crystal form a (by petrographic analysis) ...... Monoclinic

Refractive index $\left(\mathrm{N}_{\mathrm{D}}^{25}\right) \ldots$

Density _...

Fluorescence $^{\mathrm{b}}$ (excited by $3650 \mathrm{~A}$ radiation) .... White

Solubility

a Figure 3 and 4, respectively, show zinc eugenolate crystals and electron micrographs of a zinc oxide-eugenol mixture.

$\mathrm{b}$ The presence of zine eugenolate may be readily detected by means of the characteristic white fluorescence emitted by this compound when excited by ultraviclet radiation. When similarly excited ainc oxide and eugenol fluoresee ultraviolet radiation. When similarly excited, zinc oxide and eugenol fluoresce bright yellow and dark brown, respectively. A mixture of zinc oxide and eugenol uoresces deep re

in soluble hot chloroform; soluble in ammonium hydroxide, pyrdine, hot acetamide, and hot butyrolactone.

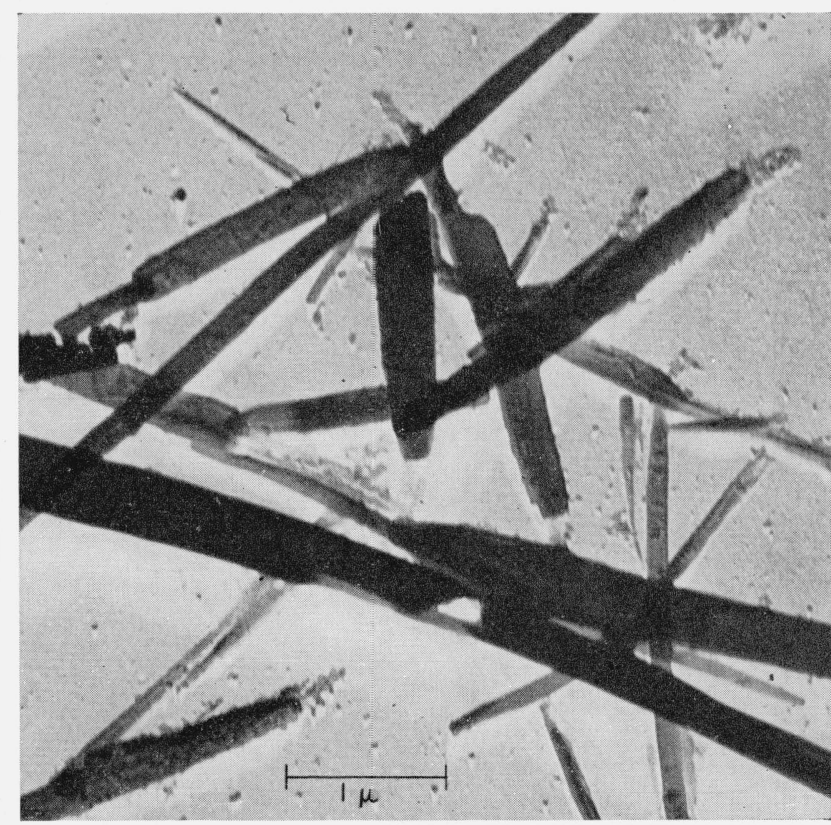

Figure 3. Electron micrograph of zinc eugenolate, palladium shadowed 4:1, showing the crystal habit typical of the extracted reaction product.

The small, rounded particles seen in the background and on the surfaces of the large, crystalline for mations are probably zine oxide. 
Figure 4. Electron micrograph of a zinc oxide-eugenol mixture showing the small, rounded particles of zinc oxide and the thin, elongated crystals of zinc eugenolate.

The sheaf-like aggregation is typical of the unextracted hardened mass.

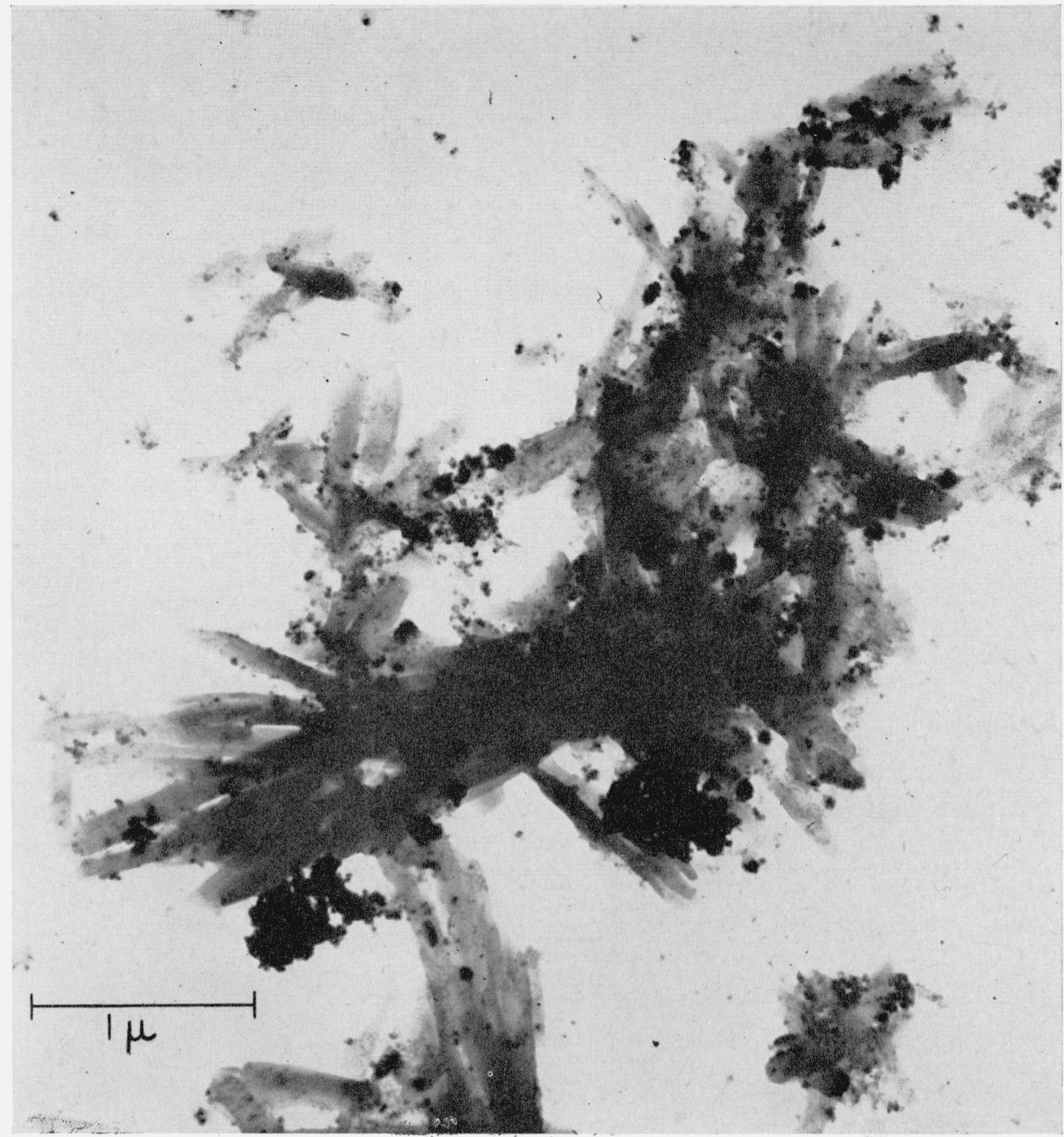

Zinc is a bivalent element with a common coordination number of four. As such, zinc is a metal likely to form a chelate. Eugenol, guaiacol, and methylguaiacol have a replaceable hydrogen and a nearby donor in the oxygen of the o-methoxy group. The chelate formed would have a proportion of two eugenol molecules to one zinc. It may be represented as follows:<smiles>C=CCc1ccc(O[14C]2(C)Oc3ccc(CC=C)cc3O[13C]2(C)OC)c(OC)c1</smiles>

The compound did not sorb an appreciable amount of water on storage in a high-humidity $(93.3 \%)$ 

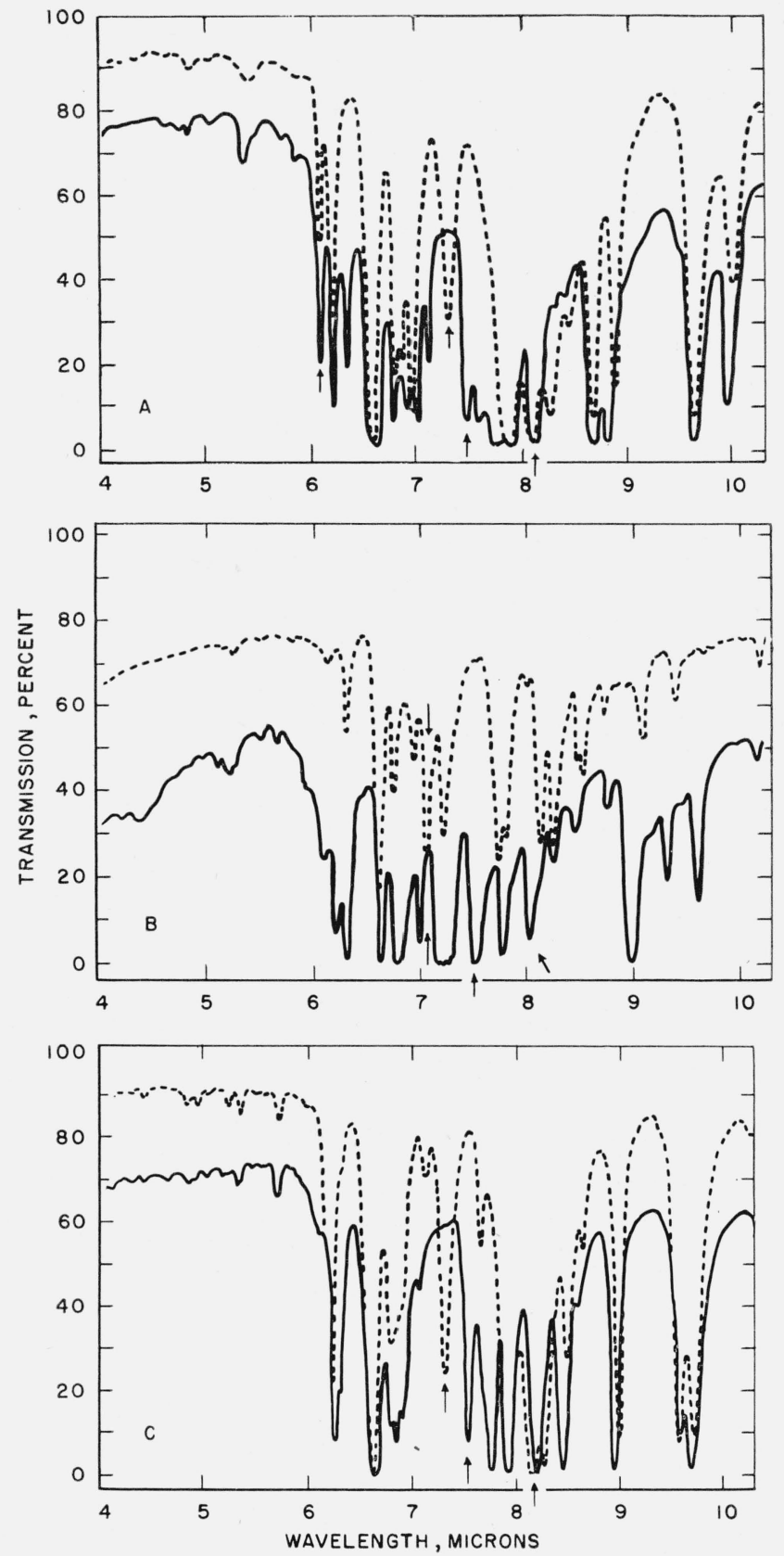

FiguRE 5. Infrared absorption spectra.

In each case the broken line is the hydroxy aromatic and the solid lin is the zinc derivative. A, Eugenol and zinc eugenolate; B, 8-quinolinol and zinc quinolinolate; $\mathrm{C}$, guaiacol and zinc guaiacolate.

atmosphere for 10 days. Therefore, the formation of a hydrate at room temperature is not likely to occur.

The set mass resulting from an equimolar mixture of zinc oxide and eugenol contains zinc oxide, zinc eugenolate, and eugenol. The recovery of eugenol from the extraction procedures shows the presence of excess eugenol. A comparison of data from the extraction procedures and X-ray diffraction pattern 3 of figure 1 indicates that only a portion of the zinc eugenolate formed was recovered by the extraction procedures, and both methods show the presence of a considerable amount of unreacted zinc oxide. The sheath-like zine eugenolate crystals formed act as a matrix for the zinc oxide. Excess eugenol is sorbed by the zinc eugenolate and likely sorbed by the zinc oxide. Sorption of eugenol by zinc eugenolate is demonstrated by paste formation when zinc eugenolate crystals are dispersed in eugenol.

\section{Summary}

1. The setting of mixtures of zinc oxide and eugenol involves both physical and chemical processes.

2. X-ray diffraction data and electron photomicrographs give evidence that a crystalline compound is formed by the chemical reaction.

3. Chemical analysis and molecular weight determinations show that this crystalline compound corresponds to the empirical formula $\left(\mathrm{C}_{10} \mathrm{H}_{11} \mathrm{O}_{2}\right)_{2} \mathrm{Zn}$, zinc eugenolate.

4. Infrared absorption data suggest that zinc eugenolate is a chelate compound with the following structure:

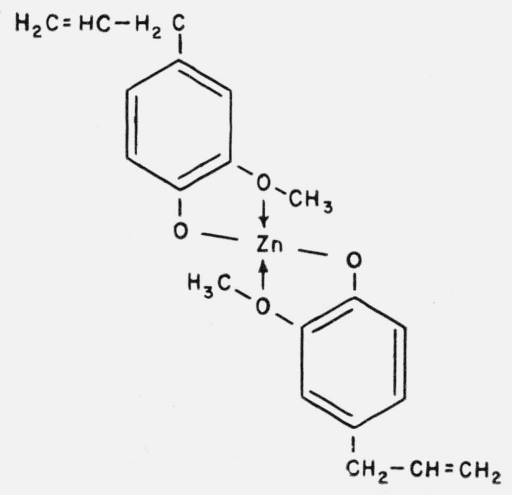

5. The set mass resulting from mixes of zinc oxide and eugenol consists of zinc oxide embedded in a matrix of long, sheath-like crystals of zinc eugenolate. The excess eugenol is likely sorbed by both the zinc eugenolate and the zinc oxide.

The authors especially acknowledge the generous assistance given by $\mathrm{H}$. Swanson and $\mathrm{G}$. Ugrinic of the Microstructure Section, National Bureau of Standards, in performing X-ray diffraction measurements.

The authors thank J. B. Conn of Merck and Co., Inc., for supplying the Hyperfine zinc oxide.

\section{References}

[1] H. J. Turkheim, Brit. Dental J. 45, 1 (1953).

[2] E. Forster, Stomatologia 27, 217 (1929).

[3] W. Harvey and N. J. Petch, Brit. Dental J. 80, 1, 35 (1946).

[4] F. Zetzsche, H. Silbermann, and G. Vieli, Helv. Chim. Acta 8, 596 (1925).

[5] H. E. Swanson and R. Fuyat, NBS Circular 539, vol. II (1953).

[6] L. Merrit, Jr., Anal. Chem. 25, 718 (1953)

[7] A. E. Martell and M. Calvin, Chemistry of Metal Chelates (Prentice-Hall Inc., New York, N. Y., 1952).

Washington, April 1, 1955. 